\title{
SOME REFLECTIONS ON THE USE OF THE NATIVE LANGUAGE IN ELEMENTARY LANGUAGE TEACHING
}

\author{
Robert L. Politzer \\ Department of Romance Languages \\ University of Michigan
}

Whether or not, or to what extent, the native language of the learner should be used in the foreign language class is a perennial problem of discussion among language teachers. Some language teachers-especially those who believe in the so-called "direct method"-make the exclusive use of the foreign language the main feature of their teaching and condemn use of the native language quite categorically. Most linguists concerned with language teaching have generally been less categorical in condemning the use of the native language and have admitted it for certain purposes. 1 What are then the possible uses of the native language, and what are the main dangers connected with the use of the native language? This short article does not pretend either to exhaust the subject or to present the views of "linguistics" on that subject; it merely gives the reflections of one linguist, who has for some years been concerned with foreign language teaching in general, and more specifically with the teaching of French to native speakers of English.

I and probably most language teachers, linguist or nonlinguist, believe that the foreign language class should afford a maximum of active practice in the foreign language. Those of us who are linguists have come to the conclusion that this practice should be directed toward acquiring specific sentence patterns in the foreign language, and should concentrate systematically on the points of difficulty: those sounds, vocabulary problems or structures in which the foreign language clashes with the native language of the learner.2 As a general rule I believe that the native language is used to advantage if it frees additional classroom time for that type of practice. Some of the major reasons for the use of the native language are therefore the following:

1. Certain phases of classroom instruction can be accomplished more economically in the native language. Two possible uses of the native language come to my mind under this heading of economy: 
(a) It may be possible (we can never be sure) to explain a grammatical problem or a contrast between the native language and the foreign language in the foreign language itself. And it may also be quite possible, let us say, to explain to a speaker of English the difference between German $D u$ and Sie, or French vous and tu using only the context or an explanation in either German or French; but the process of making such a difference clear will undoubtedly take more time than a quick explanation in English. Now it is quite possible that the mere fact that the explanation is given in the foreign language may afford a certain amount of practice in the foreign language, but that practice is not organized around specific problems, it is not part of the learning scheme-chances are that the class time gained by explaining in English could be used more effectively in the drill of specific materials.

(b) Translation is still the most economical way of supplying the approximate meaning of lexical items in the foreign language. As a linguist I feel that the most serious problem in the learning of the foreign language is acquisition of structure and not the learning of vocabulary. Again it seems uneconomical to me to devote a large amount of class time to the somewhat roundabout and tedious explanation of a lexical item, if this lexical item could be explained to the student by merely giving him an approximate equivalent in his native languageand class time would be freed for drill in the realm of structure.

2. Some possible uses of the native language go beyond the realm of mere economy but have inherent pedagogical justification. Difficulties in the foreign language usually revolve around some contrast between the native and foreign languages. The use of the native language makes it possible to focus attention on those contrasts and drive those contrasts home to the learner. Like some other principles of applied linguistics the possibility (or necessity) of using the native language is most obvious in the realm of phonology. If we use the foreign language alone, then we can teach production of the sounds of the foreign language and practice exercises which train the student in discrimination between the sounds of the language to be learned. But this is not enough. Let us say we teach Spanish or German to a speaker of English. The speaker of English, who has five front vowel phonemes (i $I$ e $\varepsilon æ$ ) as compared to the two (i e) of Spanish or the two (i, e, also differentiated by length) of German, has no problem of auditory discrimination whatsoever. His problem is purely one of substituting English sounds for German or Spanish sounds, and in order to avoid his substituting the English sounds he must 
hear the difference between English and the foreign language. In other words, to drill him in auditory discrimination between, for example, German Sie and See is largely a waste of time; what he must learn is the difference between the German See and English "say", German geh and English "gay", etc.

Now this principle of overtly contrasting in drill fashion the native and the foreign language can also be applied to teaching of structure. An exercise in which the teacher asks the student to give, for instance, the equivalent of "I want John to study, I want Charles to study, I want John to work, I want Charles to work," etc., and the student answers with ich möchte dass Johann studiert, ich möchte dass Karl studiert, etc. ( je veux que Jean étudie, je veux que Charles étudie, etc.), actually highlights and drills quite economically an important structural difference between the languages involved.

Another important use of the native language is, I think, implied in what I have just said. The native language may sometimes be the most efficient means to evoke student response in a pattern drill exercise. The way in which such pattern drill is usually carried out is by techniques such as substitution or conversion: the student is given a pattern like je veux que vous cherchiez le livre or ich möchte dass Sie das Buch suchen, and is asked to replace vous or Sie by another form, or to replace livre or Buch by another noun; or we ask the student to make a series of positive statements negative, or to convert a series of statements into questions, etc. But giving the student a pattern in his native language and asking him to respond in the foreign language is just as easy a way to drill the pattern, and assures that the student thoroughly understands the meaning of the foreign pattern-something which is not always assured by the substitution technique alone. The very advantage of the substitution technique, namely that it is mechanical, may prove a disadvantage, for a student can go through an entire exercise correctly without really knowing what he is saying. The use of the native language is thus a good supplement to the purely mechanical substitution or conversion procedures.

The real reason for the opposition to the use of the native language is perhaps justified by the great ease with which the native language can be misused or abused in the classroom. So let us list briefly what I consider the ways in which the native language can be misused in the foreign language class. Before I begin, I wish to make it clear again that I think that the native language should be used only to recall a pattern already learned, or to bring about a modification or substitution in such a pattern. 
1. The native language should not be used as a basis for translation in the sense that the student (perhaps with the help of some grammatical "rules") is asked to construct a new pattern. A pattern in a foreign language must be learned and not "constructed." I think that the teacher using the native language must be on constant guard that he (and just as important, his student) is not using the native language that way. The student who in response to a stimulus like "I am going to school" starts to answer slowly, looking for partial equivalents to the English sentence ( $j e$ suis...., ich bin....) must be stopped immediately, be given the correct response by his teacher or a classmate, and put back on the right track by repeating the drill that makes him respond rapidly to "I am going to school, I am going to church," etc.

2. The native language should, I think, be used orally only. There are at least two reasons for insisting on oral use. Using the native language only orally minimizes the danger of using it as a basis for word to word translation. The native language should be a stimulus for the students to respond in a pattern of the foreign language. However, the native language written out gives the student time to "figure out" partial equivalents of the statement in the native language to the foreign language; it gives him time to restructure the foreign language in terms of his own. The other reason for using oral rather than written language is simply that signals of the native language may exist only in speech and have no written equivalent. By using the written language we throw away the possibility of making important distinctions which facilitate the learning problem; for instance, there is for a speaker of English a rather selfevident distinction between a Freńch teàcher (primary stress on French) and a Freñch teácher (primary stress on teacher), between a Gérman teacher and a Germán teácher. In those languages, however, they become un professeur de francais vs. un professeur français, and ein Deutschlehrer vs. ein deutscher Lehrer. I remember struggling in vain to explain to a class the difference between un livre français and un livre de francais, and I remember telling them that un livre de francais was a book concerned with French, while un livre français was a book written in French and came from France. I also remember that a student in my class became very indignant when I corrected j'ai fait le connaissance d'une jeune fille de français in one of his compositicns. He pointed out to me that this girl had not come from France, but from Canada, but that she was very much concerned with French, etc. When I pointed out to him the simple correspondence between French bóok (livre francais) and Frenc̀ gírl, he caught on immediately. 
3. I have stated above that the positive advantage of the use of the native language lies in stressing the contrast between that language and the foreign language. One habit that is unfortunately quite frequently found in many textbooks works directly counter to this, namely the idea of adapting the native language to the foreign language. We must never attempt to structure the native language to fit the patterns of the foreign language. This habit of adapting the native language may take two forms:

(a) In some instances actual violence is done to the native language and it is presented in a form which would hardly ever, if at all, be used in actual speech. For example, the use of written rather than oral language may be responsible for this: in English, stress may be used to emphasize the importance of one particular part of the sentence. "I want to do this today" vs. "I want to do thís today" vs. "I want to do this todáy" give us different meanings. French does not utilize stress in this particular way. What is necessary in French is a different construction: c'est moi qui veux faire cela aujourd'hui vs. c'est cela que je veux faire aujourd'hui vs. c'est aujourd'hui que je veux faire cela. Many French grammar books that I have seen attempt to have the student produce these French patterns by having him translate "it is I who want to do this," "it is today that I want to do this," etc. This way of manipulating English not only does violence to the language, it also fails to teach the student when really to use the French construction. Since it seems to correspond to something he would never use in English anyway, he will probably not use it in French, andunless explicitly warned-will continue to attempt to express emphasis and importance in French by using a stress accent, a procedure which will be quite meaningless to his possible French listeners. I also wonder whether the student who is asked to translate into French or German "one tells me that you are right" will ever learn to use the French on or German man-unless it has been signalled by this particular construction. I know that students who translate "one tells me that you are right" beautifully into on me dit que vous avez raison, will come up in free composition or conversations with such strange constructions as ils me disent or even je suis dit-the literal translation of "they tell me" or "I am told," which are of course the normal and frequently used English counterparts of the French on construction.

(b) Another more subtle way of adapting the native language to the foreign language is the constant use, not of an unusual or unnatural construction, but of a construction which has a parallel in the foreign language and the avoidance of the 
corresponding construction that clashes. Thus we can always avoid a construction like "he could have gone" in favor of "he would have been able to go" in order to accommodate the French il aurait pu aller, or German er hätte gehen können (past conditional plus infinitive). I have also noticed that in almost all French grammars the indirect object of English is always marked by the preposition "to" because "I give the book to Charles" corresponds nicely to je donne le livre $a$ Charles. But this does not, alas! keep our students of French from doing violence to French by saying je donne Charles le livre whenever they happen to be influenced by the English construction "I give Charles the book."

4. Some structures of the native language may have no obvious counterpart in the foreign language. In such instances it is doubly necessary to contrast the native language and the foreign language and point out that a specific construction has no direct counterpart and may not be used. For instance, a speaker of English may learn and observe in French or German grammars and conversation books that a question like Avezvous vu le livre? (Haben Sie das Buch gesehen?) will evoke answers like Oui or Oui, je l'ai vu (Ja, or Ja, ich habe es gesehen). All of these have English counterparts: "Yes," or "Yes, I have seen it," but in addition, the student must be taught quite specifically that the most common English response, "Yes, I have" (or "No, I haven't") has no counterpart in either French or German, where the entire verb of the question must be repeated in the answer. A drill which contrasts French Oui or German Ja with English responses like "Yes, I have" or "Yes, I am" can make this point quite emphatically.

5 . Connected with the use of written rather than oral language as a basis for instruction is quite often the attempt to be prescriptive in the native language. It is the way in which the native language is actually spoken which must be contrasted with the foreign language. To compare the foreign language not with the way in which the student speaks but with the way in which he ought to speak confuses the issue and makes our job more difficult. Many French grammars offer lengthy explanations of the difference between English "I should give" (which equals je donnerais), and the other English "I should give" (which means je devrais donner) 3 In German the two "should give's" of English are also considered to have two different equivalents: ich würde geben vs. ich soll(te) geben. Now je donnerais equals, of course, "I'd give," and je devrai donner is "I ought to give," a difference which is clear to any speaker of English. If a writer of a textbook thinks that the "first 
person conditional" of English is, or ought to be, "should give," and introduces this into his book, he will only confuse the student. A textbook writer who attempts to explain to the student the difference between "will" indicating volition, vs. "will" indicating the future4 (he will give = il veut donner vs. il donnera) could save himself and his students some trouble by teaching the English future as "he is going to give," which is of course the form normally used.

A final word: I am sure that all linguists and language teachers will agree on one point. The main danger of the use of the native language is simply that it is easy to overdo it. We should not lose sight of my initial statement that the main advantage of the use of the native language is to free class time for specific concentrated drill in foreign language patterns. There is of course no magic formula telling us how much English is permissible or advisable in, let us say, French or German class, but it is obvious that the class time must be used for imitating and responding to French or German patterns. I personally would be quite worried if more than ten percent of a foreign language class were taken up by a student listening to his native language.

The application of linguistics to language teaching lies primarily in this intensive drill of specific structural difficulties. The usual classification of teaching methods puts the emphasis rather on how the semantic content of a sentence or structure is supplied to the student. Thus some teachers, advocates of the so-called direct method, will boast that they never use a single word of the native language in the classroom. But this in itself is not a guarantee for the most efficient teaching. A teacher who uses pictures to evoke answers in the foreign language, but uses them without reference to specific drill, and in addition allows the student considerable reaction time for his answer is deceiving himself about the student's native language not being used in his classroom. For most of his students will respond first mentally in their native language, and then proceed to translate silently in order to give the required response. And on the other hand, I believe that a teacher may use the native language to evoke the type of pattern drill I have suggested above, and his students, automatically responding in the foreign language, will actually make less use of their native language in acquiring fluency in the use of the structures of the foreign language. 


\section{FOOTNOTES}

1. See for instance A. Hill, "Language Analysis and Language Teaching," $M L J$, XL (1956), 335-345, especially p. 345: "A sensible plan, instead of the direct method, is initial explanation, as accurate and simple as possible in the native language, followed by drill aimed at the acquisition of patterns."

2. See Robert Lado's book, Linguistics across Cultures, Ann Arbor, 1957, for a complete treatment of the principle of interlingual comparison as a basis for the construction of teaching materials.

3. J. Harris and A. Lévèque, Basic Conversational French, New York, 1957, p. 154: "While it is generally bad practice to think of French words and phrases in terms of their supposed English equivalents, it is particularly dangerous in the case of should and would. While these words are indeed used to form a conditional in English, they have other very common meanings which have nothing whatever to do with the conditional."

4. E. Sonnet and G. Shortliffe, Review of Standard French, New York, 1954, p. 178: "It is very important to distinguish between will and would used as auxiliaries of the future or conditional and will and would expressing volition. In this last case will and would are real verbs." 